\title{
The Relation between the Teaching of Mathematics and Statistics in the Republic of South Africa
}

\author{
By Lukanda Kalobo*
}

\begin{abstract}
The purpose of this study is to explore the relation between the teaching of Mathematics and the teaching of Statistics at high school level in the South African Context. The study also examines and analyses examples of statistical teaching situations from both a mathematical and a statistical perspective with view to reveal the links between the teaching of Mathematics and teaching of Statistics. A non-empirical method or conceptual method was followed to achieve the purposes of the study. The study reveals the cardinal links between the teaching of Mathematics and teaching of Statistics. Hence the call to educators to acknowledge the symbiosis to enhance the teaching and promote an awareness of the ways in which Statistics is presented and aligned in the South African Mathematics high school Curriculum.
\end{abstract}

Keywords: teaching mathematics, teaching statistics, high school, South Africa context

\section{Introduction}

It is not astonishing that in South Africa, Statistics instruction at High school is compulsory for all learners taking Mathematics. Statistics is a part of the Mathematics curricula in basic education (DBE, 2005). According to Burril (2011), the goal of teaching Statistics is to foster an adult population capable of reasoning from, and about data and making informed decisions based on quantitative information in the workplace, in their personal lives and as citizens. Furthermore, Citizens are being called upon to make increasingly complex decisions about policies and practices in the socio-political, workplace, and consumer arenas (Franklin \& Garfield, 2006; Kader \& Perry, 2006). Thus, the teaching of Statistics provides learners with tools and ideas to use to react intelligently to quantitative information in their world (Ben-Zvi \& Garfield, 2008). At the other end Mathematics helps to develop mental processes that enhance logical and critical thinking, accuracy and problem solving that will contribute in decision -making (DBE, 2011). According to DBE (2011) Mathematics problem solving enables us to understand the world (physical, social, and economical) around us, and, most of all, to teach us to think creativity. The goal of mathematical instruction should be to make students sensible, critical users of Statistics, able to apply their processes and principles to real-world problems (Mathematics Curriculum Framework, 1996). This is manifest in the South African Mathematics Curriculum and Assessment Policy Statement (CAPS), with one of the aims is to collect, analyse, organize, and critically evaluate information (DBE, 2011). This study emphasizes

\footnotetext{
*Senior Lecturer, Central University of Technology, Free State, South Africa.
} 
on the need to explore the relation between the teaching of Mathematics and the teaching of Statistics at high school level in the South African context.

\section{The Teaching of Mathematics in the South African Context}

Given that there are different competing influences in Mathematics, it is important to clarify to the reader how teaching of Mathematics has been conceptualised in this paper. Pimm, Westwell, Wilder, and Wilder (2011) spoke about four Mathematics perspectives such as the industrial pragmatists, the mathematical purists, the progressive educators, and the social reformers. This study presents extracts that include brief descriptions of Mathematics perspectives, published in Mathematics education literature, from the progressive educators, and the social reformers. Conferring to Pimm, Westwell, Wilder, and Wilder (2011), the progressive educators are concerned with the personal development of pupils, with the individual child as the focus of attention. Additionally, Berry III and Ellis (2005) agreed that the progressive educators assert that children should have the freedom to develop naturally; interest should be the motivation for all work, and the teacher is a guide and not a taskmaster. Pimm, Westwell, Wilder, and Wilder (2011) revealed that the teacher's role is perceived by the progressive educators as guiding the learners on their journeys of discovery contexts. Pimm, Westwell, Wilder, and Wilder. (2011) explained that the social reformers are concerned with the social development of pupils, in the sense that education should empower the individual to participate fully and critically in a democratic society. Furthermore, Ernest (1991, p. 207) confirmed that this group views Mathematics as a social construction: tentative, growing by means of human creation and decision-making, and connected with other realms of knowledge, culture, and social life. Additionally, for Pimm, Westwell, Wilder, and Wilder (2011) the social reformers perceive the teacher's role as facilitating learners in both posing and solving their own problem contexts. Moreover, any form of assessment must be seen to be fair to all pupils and should not disadvantage any social group. This require a greater variety of modes of assessment and so project work and the ongoing assessment of coursework is highly valued (Pimm, Westwell, Wilder, and Wilder, 2011). Thus, the South African views of Mathematics are closely associated with those of the progressive educators and the social reformers. The South African Curriculum has recently been restructured to reflect the values and principles of a democratic society. In view of the country's history and legacy of inequality, curricula have been developed to accommodate the widely different groups (Steffens \& Fletcher, 1999). In South Africa, the Mathematics Curriculum is concerned about the personal development of learners. This Curriculum supports a learner-centred teaching approach whereby the teacher is the one that exposes learners to mathematical experiences that give them many opportunities to develop their mathematical reasoning and creative skills in preparation for more abstract Mathematics in Higher/Tertiary Education institutions (DBE, 2011). Furthermore, the Curriculum promotes the participation of learners as responsible citizens in the life of local, national, and global communities; use mathematical process skills to 
identify, investigate and solve problems creatively and critically (DBE, 2011). Moreover, according to DBE (2011), the Mathematics Curriculum views assessment as a continuous planned process of identifying, gathering and interpreting information about the performance of learners, using various forms of assessment. The teachers' conception of Mathematics significantly influences how they teach it. Furthermore, these DBE's views have been supported by Beckmann, Thompson, and Rubenstein (2010), acknowledging that teaching Mathematics means supporting learners as they learn to think more and more about Mathematics notions, processes, applications, and relationships.

\section{The Teaching of Statistics in the South African Context}

Today, decisions are made based on data (Ramachandran \& Tsokos, 2021). Doing Statistics involves many primarily nonmathematical activities, such as building meaning for data by examining the context and choosing appropriate study designs to answer questions of interest (Growth, 2007). According to Burril (2011), the aim of teaching Statistics is to foster an adult population capable of reasoning from, and about data and making informed decisions based on quantitative information in the workplace, in their personal lives and as citizens. The teaching of Statistics provides learners with tools and ideas to use to react intelligently to quantitative information in their world. Burril (1996) revealed that in teaching Statistics attention must also be paid to the didactics of the Statistics classroom, and statistical concepts should be learned over time beginning with early and informal experiences. According to Del Mas (2002), using statistical literacy, reasoning, and thinking to distinguish between desired learning outcomes in Statistics is extremely helpful both in considering instructional goals and in writing assessment items. Statistical literacy includes basic and important skills that may be used in understanding statistical information or research results (Chance, Del Mas, \& Garfield, 2003). One of the ways that seems especially favoured to help students develop their statistical reasoning is to incorporate active-learning strategies where students can practice Statistics by designing a study, collecting data, analysing the results and preparing reports, even giving oral presentations. This aids in building students' sense of responsibility for learning and turns them into active constructors of their education (Cobb, 1993). Statistical thinking is promoted when instruction challenges learners to apply their understanding to real-world problems, to critique and evaluate the design and conclusions of studies, or to generalize knowledge obtained from classroom examples to new and somewhat novel situations (Chance, 2002). Incorporating real data and interesting examples, whether into a separate statistics course or within the context of another subject, is a great way to expose students to the critical thinking skills required of statistical analysis. They can then use the skills in other courses, research, or simply everyday life (Capaldi, 2019). 


\section{Constructivist Approach in the Teaching of Statistics}

Constructivism has been a very powerful model for explaining how knowledge is produced in the world as well as how students learn (Shah, 2019). It is an approach to learning that holds that people actively construct or make their own knowledge and that reality is determined by the experiences of the learner's (Elliott, Kratochwill, Littlefield, \& Travers, 2000). This constructivist view implies that learners work actively towards constructing their own knowledge and combining it with the knowledge they already have (Moore, 1997). One of the general aims of the South African Curriculum is to encourage an active and critical approach to learning, rather than rote and uncritical learning of given truths (DBE, 2011). Constructivism's central idea is that human learning is constructed, that learners build new knowledge upon the foundation of previous learning. Additionally, Shah (2019) clarified that learners, through social negotiation, continuously test their hypotheses and create new knowledge, correct previous knowledge, or confirm present knowledge. Learner linked new knowledge to prior knowledge. This educational view changes not only the learners' but also the teachers' perspective in Mathematics. Effective learning of mathematics requires that students understand what they know and need to learn, and this motivation will help them learn more (Bhowmik, 2015, Jazim, Anwar, \& Rahmawati, 2017). Moore (1997) proposes a shift from a theoretical approach to a more direct way of learning in Mathematics. Based on the relevant research in the context of constructivist principles, Garfield (1995) formulated general principles of learning Statistics based on constructivism practice. Constructivist practice is thus applied in both teaching Mathematics and teaching Statistics. In the South African context, there is a need for the teacher to acknowledge that constructivist practice plays an important role in the teaching of Mathematics and in the teaching of Statistics in the Mathematics Curriculum. In the present study, we refer specifically to social constructivism, because the view that knowledge is socially constructed is the theoretical basis for interactive-learning classrooms in which students work in small-groups to solve problems and create an understanding of the material (Bargera, Perez, Canelas, \& Linnenbrink-Garcia, 2018).

\section{Statistical Teaching Situations from Both a Mathematical and a Statistical Perspective}

\section{Existing Knowledge}

The focus of teaching and learning Statistics at high school is built on what was learned previously in lower grades (DBE, 2003). Therefore, learners come to high school with the existing knowledge of Mathematics or Statistics from previous Grades. Gattuso (2006) confirms that it is essential to highlight the mathematical concepts underlying the statistical concepts, in order to link both in creating classroom activities. If learners' initial ideas and beliefs are ignored, the understandings that they develop can differ a great deal from the teacher's intentions. 
For example, learners are asked to represent the data of COVID-19 death cases in South Africa in a box plot format (see Table 1). The box plot (see Figure 1) is used to examine data. This format is often referred to as a box-and-whisker plot. Box plots are useful for comparing different sets of data (Triola, 2011, p. 122).

Table 1. COVID-19 Pandemic in South Africa

\begin{tabular}{|l|c|}
\hline Date & Deaths \\
\hline $2020-05-25$ & 481 \\
\hline $2020-05-26$ & 524 \\
\hline $2020-05-27$ & 552 \\
\hline $2020-05-28$ & 577 \\
\hline $2020-05-29$ & 611 \\
\hline $2020-05-30$ & 643 \\
\hline $2020-05-31$ & 683 \\
\hline $2020-06-01$ & 705 \\
\hline $2020-06-02$ & 755 \\
\hline $2020-06-03$ & 792 \\
\hline $2020-06-04$ & 848 \\
\hline $2020-06-05$ & 908 \\
\hline $2020-06-06$ & 952 \\
\hline $2020-06-07$ & 998 \\
\hline $2020-06-08$ & 1080 \\
\hline
\end{tabular}

$481,524,552,577,611,643,683,705,755,792,848,908,952,998,1080$

The learners should conclude that the minimum is 481 and the maximum is 1080. The first quartile involves the concept of percentage. In this instance, learners need to find the $25^{\text {th }}$ percentile of a given data.

Let $\mathrm{h}$ be the total. Let $\mathrm{k}$ be the percentile being used, $\mathrm{L}$ the position of value, $P_{k}$ the $k^{t h}$ percentile. So $L=k \times h, k=\frac{25}{100}, h=15$ this implies that $L=$ $\frac{25}{100} \times 15=3.75$. Thus $Q_{1}=577$. The second quartile involves $50^{\text {th }}$ percentile. Learners must remember how to calculate $50 \%$ of a given amount. This implies that $L=\frac{50}{100} \times 15=7.5$. Thus $Q_{2}=705$. Similarly, $Q_{3}=908$.

Figure 1. The Box-and-Whisker Plot Representing the Population Age

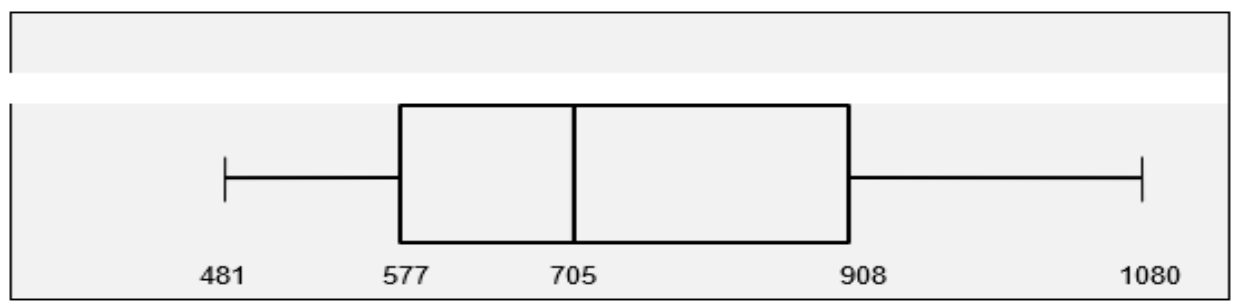

Therefore, the statistical concept of the five number summary can be introduced. The box plot representing the data can be drawn and this five number 
summary can be interpreted. The link between the teaching of Mathematics and the teaching of Statistics is evident in the prior mathematical knowledge needed by the learners in Statistics to find the minimum $(\mathrm{min}=481)$ and maximum $(\max =1080)$; the calculations of $25 \%(\mathrm{Q} 1=577)$, the $50 \%(\mathrm{Q} 2=705)$ and the $75 \%$ $(\mathrm{Q} 3=908)$ of a given set of data that will lead to the representation of the box plot and the interpretation of the data.

According to Gattuso (2006), it is important to let the learners explore situations in which they collect, organise, and represent their own data, and make them realise the elements that are essential and those such as titles and scales that are missing. Once they display their own data in a graph or table, it is time to interpret it. This may start with counting and proceed to comparisons. This viewpoint is in line with the constructivist approach to instructional design where the teaching and learning of new concepts is based on existing knowledge.

\section{Problem Solving}

Problem solving helps a learner master a concept and that instruction should not separate Mathematics from its applications (Gattuso, 2006). Due to its importance, there have been calls for the teaching of problem-solving, as well as the teaching of mathematics, through problem-solving to be included in the mathematics curriculum (Liljedahl, Santos-Trogo Malaspina, \& Bruder, 2016). According to Krulik and Posamentier (1998), the following strategies are applied to an everyday problem-solving situation in Mathematics: working backwards; finding a pattern; adopting a different point of view; solving a simple analogous problem; considering extreme cases; making a drawing; intelligent guessing and testing; accounting for all possibilities; organizing data, and logical reasoning. The study of Statistics can be fully integrated into the Mathematics Curriculum, giving it meaning related to everyday life (Gattuso, 2006). Statistical activities in the classroom can be directly linked to the learners' personal interests and stimulate their motivation for numerical and quantitative studies. These activities can be used for learning, practice, assessment, and problem-solving. The following examples illustrate the use of some problem- solving strategies in Statistics such as organizing data strategy and making drawing strategy.

\section{Organizing Data Strategy}

For example, the last seven Easter periods (from 2014 to 2020) have seen car accident fatalities over the Easter weekend.

$$
27,30,29,25,27,38,28 .
$$

Find the median for the following group of 7 Easter periods car accident fatalities. Learners can use the organizing data strategy. The way the data have been listed makes it difficult to find the median directly. However, if the data are organised in increasing/decreasing order, the middle or median is found.

$25,27,27,28,29,30,38$ 
The middle or median of the data is equal to 28 . In doing so, learners not only enhance their understanding of Mathematics but also get in touch with another discipline such Statistics (Gattuso, 2006).

\section{Making Drawing Strategy}

For example, views on the handling of the pandemic by the South African Government: $48 \%$ of respondents feel that the Government has handled the lockdown and pandemic crisis very well, while $52 \%$ believe it has not been handled well at all. Display and compare the given data. The data associated with this question could be represented by means of a pie chart (Figure 2), using the making drawing strategy as a problem-solving strategy. A pie graph is a circle in which the slices represent percentages (Steinberg, 2008). This will require the use of proportions: 48 out of 100 respondents play soccer (48/100) and 52 out of 100 (52/100). These fractions need to be converted into equivalent fractions as part of the whole $360^{\circ}$, an operation that requires proportional reasoning. Learners are given an opportunity to work with fractions, carry out multiplication to find the portion of $360^{\circ}$ that will represent a particular characteristic and draw the corresponding sector of the pie. To draw the pie charts, the following steps can be taken: The proportion are: $\frac{48}{100}$ and $\frac{52}{100}$. The "regle de trois" (Hersant, 2001) can be used to find the equivalent fraction of $360^{\circ} .100^{\circ}$ correspond to $360^{\circ}$. Thus $48 \%$ correspond to $\frac{360^{0} \times 48}{100}=172.8^{0}$ and $52 \%$ correspond to $\frac{360^{0} \times 52}{100}=187.2^{0}$.

Figure 2. A Pie Chart Representing the Handling of COVID-19 Pandemic in South Africa

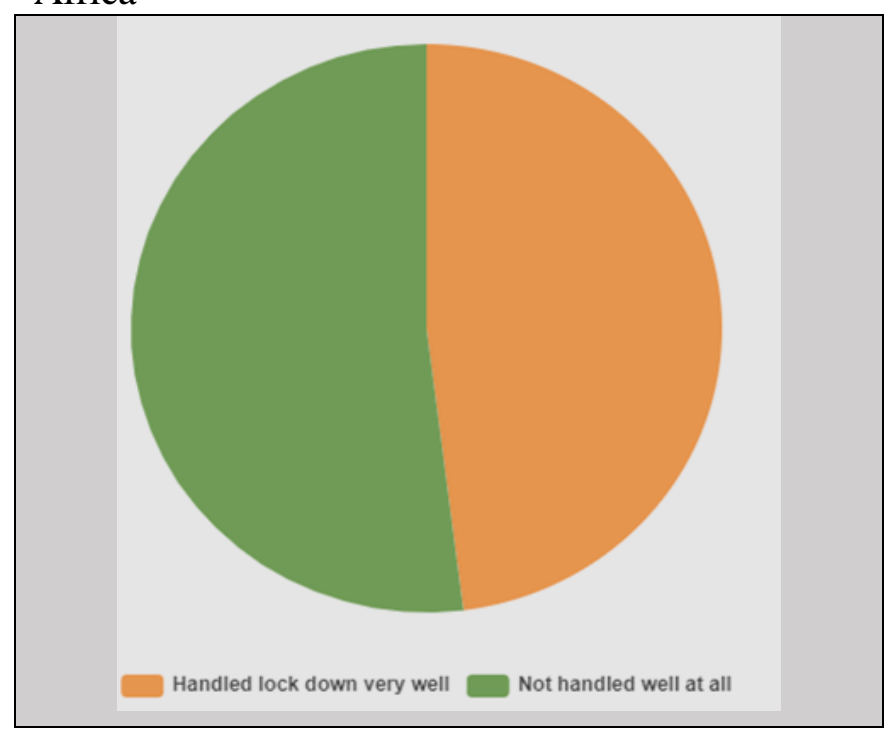

The pie chart shows that $172.8^{0}$ represent the $48 \%$ of respondents who feel that the government has handled the lockdown and pandemic crisis very well. $187.2^{0}$. While the pie chart displays $187.2^{0}$ representing $52 \%$ of respondents believe it has not been handled well at all. 
The above discussion shows that the problem solving requires a variety of skills including interpreting information, planning, and methodical working, checking results, and trying alternative strategies (Muir, Beswick, \& Williamson, 2008). A teachers' understanding and recognition of students' problem solving strategies used in the problem solving-Mathematics classroom, therefore, should be promoted and this can also be done in the Statistics classroom. It can be concluded that problem solving is an attempt to find a way out of a difficulty, achieving goals that are not immediately attainable (Rohmah \& Sutiarso, 2018).

\section{Cooperative Group Work}

Cooperative group work can be used in both Mathematics and Statistics activities. Cooperative group work occurs when learners work in small groups to help each other learn. Researchers have found that cooperative group work can be an effective strategy for improving achievement (Santrock, 2009). According to Ben-Zvi and Garfield (2008), conducting a cooperative lesson typically involves four steps: Making pre-instructional decisions about the lesson; Explaining the task and cooperative structure to learners; Monitoring and, if necessary, intervening with each learning group after the lesson; Processing and evaluating learner achievement. In South Africa, the National Curriculum Statement aims to produce learners that are able to work effectively as individuals and with others as members of a team (DBE, 2011).

\section{Conceptual and Procedural Knowledge}

Recently, the teaching process has shifted its focus towards a balance between procedural and conceptual understanding (Zakarie, 2011). Conceptual Mathematics understanding is knowledge that involves a thorough understanding of underlying and foundational concepts behind the algorithms performed in Mathematics (Hope, 2006). Students use conceptual undestanding of Mathematics when they identify and apply principles, know and apply facts and defintions, and compare and contrast related concepts (NTCM, 2000). Procedural Mathematics understanding is knowledge that focuses on skills and step-by-step procedures without explixit reference to mathematical ideas (Hope, 2006). Hope (2006) revealed that conceptual Mathematics understanding includes the knowledge of basic statistical facts. Moreover procedural understanding is representation of tasks which involve application of standard notation, representation and algorithms to solve statistical problems (Lipson, 2007). According to Lim (2002) procedural understanding can aid in understanding conceptual understanding. Every student should learn Mathematics with understanding (Hope, 2006). This might be the case with every student in learning Statistics. This is in alignment with the aims of South African Mathematics Curriculum. This Curriculum aims to ensure that children acquire and apply knowledge and skills in ways that are meaningful to their own lives. In this regard, the Mathematics Curriculum aims to produce learners that can collect, analyse, organize, and critically evaluate information; 
communicate effectively using visual, symbolic and/or language skills in various modes (DBE, 2011).

\section{Link between Statistics and Mathematics}

In South Africa, the Mathematics Curriculum consists of ten different content areas such as: Function; Number patterns, sequences, series; Finance, growth, decay; Algebra; Differential calculus; Probability; Euclidean Geometry, and Measurement; Analytical Geometry; Trigonometry; Statistics. Each content area contributes towards the acquisition of the specific skills (DBE, 2011). But these content areas are highly interconnected.

Algebra serves as one of the basic building blocks of Statistics. A natural link exists between data analysis in Statistics and algebra. Algebra is more than a set of procedures for manipulating symbols; it provides a way to explore, analyse, and represent mathematical concepts and ideas (NCTM, 2009). Algebra describes relationships that are purely mathematical or that arise in real-world phenomena and are modelled by algebraic expressions and presented on graphs. Learners' understanding of functions and graphs functions can both develop and be enhanced by addressing problems that involve data analysis and Statistics in authentic situations. Moreover, the representation on the Cartesian plane permits to link the properties of a function to those of a graph of that function. Cazorla, Silva, and Utsumi (2008) declared that analytic geometry can appear as a field of confluence of several concepts such as function, equation, and geometrical figure. Thus, Cazorla, Silva, and Utsumi (2008) concluded that there is a link between analytical geometry and Statistics.

\section{Methodology}

\section{Aims of the study}

This paper sought to explore the relation between the teaching of mathematics and the teaching of statistics at high school level in the South African Context, Furthermore, this study pursued to examine and analyse examples of statistical teaching situations from both a mathematical and a statistical perspective with view to reveal the links between the teaching of mathematics and teaching of statistics.

\section{Research Design}

This study adopted a qualitative approach. A non-empirical method was followed to achieve the aims of the study. The non-empirical method used in this paper draws on personal observations and/or experience of the author (Dan, 2017). To answer to the critical aspect of the study, the following questions were used for the critical literature review. What is the relation between the teaching of 
mathematics and statistics at high school level in the South African context? What are the statistical teaching situations from both a mathematical perspective and a statistical perspective, with view to reveal the links between the teaching of mathematics and teaching of statistics?

\section{Results}

A review of the relation between the teaching of Mathematics and the teaching of Statistics in the South African context could play a role in the teaching of Statistics at high school. Based on the aims of the study, literature review revealed that the South African views of Mathematics are closely associated with those of the progressive educators and the social reformers. Furthermore, literature review identified three desired learning outcomes in the teaching of Statistics, namely statistical literacy, statistical reasoning, and statistical thinking. This implies that teachers need: to develop learners' skills such: collect, analyse, and organise quantitative data to evaluate and critique conclusions; Communicate appropriately by using descriptions in words, graphs, symbols, tables, and diagrams. Teachers need to foster active learning by way of various alternatives approaches to teaching. Additionally, the literature review revealed that there is indeed a relation between the teaching of Statistics and the teaching of Mathematics based on the influence of constructivism, existing knowledge, problem-solving, cooperative learning, and the conceptual and procedural knowledge. Acknowledging the links between the teaching of Mathematics and the teaching of Statistics will enhance the instruction that teachers provide to their learners and promote an awareness of the ways in which Statistics is presented at high school.

\section{Discussion}

In South Africa, Statistics is part of the Mathematics Curriculum at high school, but yet Statistics differs from Mathematics. Verhoeven (2009, p. 10) revealed that the evidence that Statistics differs from Mathematics is not presented to argue that Mathematics is not important to Statistics or that Statistics should not be part of Mathematics. To the contrary, mathematics conceptual understanding forms part of the basic Statistics. The South African Mathematics Curriculum supports a learner-centred teaching approach whereby the teacher is the one that exposes learners to mathematical experiences (DBE, 2011). This is also the case for Statistics in high school, where the teachers focus on the statistical concepts and later on the method. Thus, the teacher needs to consider the Mathematics concepts involved in Statistics and discuss these with the class. This can still be done in class and bearing in mind about learners' Mathematics prior.

In the teaching of statistics, learners' statistical literacy, statistical reasoning and statistical thinking should be developed. These strictly depend on context. Verhoeven (2009, p. 10) confirms that this means that Mathematics serves 
Statistics only when it is absolutely necessary to understand statistical concepts.

\section{Conclusions}

This study explored the relation between the teaching of Mathematics and the teaching of Statistics at high school level in the South African context. Furthermore, the study examined and analysed examples of statistical teaching situations from both a mathematical and a statistical perspective with view to reveal the links between the teaching of Mathematics and teaching of Statistics. In this study, a literature review on the teaching of Mathematics and Statistics were conducted.

The findings seem to indicate that there is indeed a relation between the teaching of Statistics and the teaching of Mathematics based on the influence of constructivism, existing knowledge, problem-solving, cooperative learning, and the conceptual and procedural knowledge. The teaching Statistics could be improved if the Mathematics teachers should get to know and understand the links between the teaching of Mathematics and the teaching of Statistics in order to be able to teach Statistics more effectively. The envisaged improvement will enhance the teaching of Statistics at high school.

Therefore, Statistics must be presented in a manner that seeks to acknowledge the changes resulting from the Curriculum transformation in South Africa as well as from the developments in Statistics research abroad.

\section{References}

Bargera, M. M., Perez, T., Canelas, D. A., \& Linnenbrink-Garcia, L. (2018). Constructivism and Personal Epistemology Development in Undergraduate Chemistry Students. Learning and Individual Differences, 63(Apr), 89-101.

Beckmann, C. E., Thompson, D. R., \& Rubenstein, R. N. (2010). Teaching and Learning High School Mathematics. USA: John Wiley \& sons, Inc.

Ben-Zvi, D., \& Garfield, J. (2008). Developing Students' Statistical Reasoning: Connecting Research and Teaching. Practice. Emeryville, Califonia: Springer.

Berry III, R. Q., \& Ellis, M. (2005). The Paradigm Shift in Mathematics Education: Explanations and Implications of Reforming Conceptions of Teaching and Learning. The Mathematics Educator, 15(1), 7-17.

Bhowmik, M. (2015). Constructivism approach in mathematics teaching and assessment of mathematical understanding. Basic Research Journal of Education Research and Review, 4(1), 8-12.

Burrill, G. (1996). Graphing Calculators and their Potential for Teaching and Learning Statistics. In J. B., Garfield, \& G. Burrill (eds.), Research on the Role of Technology in Teaching and Learning Statistics (pp. 24-37). Voorburg: International Statistical Institute.

Burrill, G. (2011). The Role of Statistics in Improving Education. Retrieved from: http:// www.conkerstatistics.co.uk/iase/papers/IASE2011Paper1A.1Burrill.pdf. [Accessed 20 May 2020.]

Capaldi, M. B. (2019). Mathematics versus Statistics. Journal of Humanistic Mathematics, 9(2), 149-156. 
Cazorla, I. M., Silva, C. B., \& Utsumi, M. C. (2008). The Contribution of Statistics in Teaching the Concept of Mathematical Function. In Joint ICMI/IASE Study.

Chance, B. L. (2002). Components of Statistical Thinking and Implications for Instruction and Assessment. Journal of Statistics Education, 10(3).

Chance, B., Del Mas, R., \& Garfield, J. (2003). The Web-Based ARTIST Project. Invited Paper. San Francisco: Joint Statistical Meetings.

Cobb, G. W. (1993). Reconsidering Statistics Education: A National Science Foundation Conference. Journal of Statistics Education, 1(1).

Dan, V. (2017). Empirical and Nonempirical Methods. Wiley Online Library.

Del Mas, R. (2002). Statistical Literacy, Reasoning, and Learning. Journal of Statistics Education, 10(3).

Department of Basic Education - DBE (2003). National Curriculum Statements Grades 10-12 (General): Mathematics. Pretoria: Seriti Printing.

Department of Basic Education - DBE (2005). National Curriculum Statements Grades 10-12 (General): Mathematics. Pretoria: Seriti Printing.

Department of Basic Education - DBE (2011). Curriculum and Assessment Policy Statement (CAPS). Mathematics FET Phase. Pretoria: Department of Education.

Elliot, S. N., Kratochwill, T. R., Littlefield, J., \& Travers, J. F. (2000). Educational Psychology. Effective Teaching, Effective Learning. $3^{\text {rd }}$ Edition. London: Brown and Benchmark.

Ernest, P. (1991). The Philosophy of Mathematics Education. Basingstoke: Falmer Press.

Franklin, C., \& Garfield, J. (2006). The Guidelines for Assessment and Instruction in Statistics Education (GAISE) Project: Developing Statistics Education Guidelines for Pre K-12 and College Courses. In G. F. Burrill (ed.), Thinking and Reasoning about Data and Chance: Sixty-Eighth NCTM Yearbook (pp. 345-375). Reston, VA: National Council of Teachers of Mathematics.

Garfield, J. (1995). How Learners learn Statistics. International Statistical Review, 63(1), 25-34.

Gattuso, L. (2006). Statistics and Mathematics: Is it Possible to Create Fruitful Links? ICOTS7.

Growth, R. E. (2007). Toward a Conceptualization of Statistical Knowledge for Teaching Randall E. Growth. Journal for Research in Mathematics Education, 38(5), 427-437.

Hersant, M. (2001). Interactions Didactiques et Pratiques d'Enseignement, le Cas de la Proportionalité au College (Didactic Interactions and Practice of Teaching, the Case of Proportionality at the College). Paris: Université de Paris 7.

Hope, M. (2006). Preservice Teacher Procedural and Conceptual Understanding of Fractions and the Effects of Inquiry Based Learning on this Understanding. Unpublished Doctoral Dissertation. Clemson University.

Jazim, Anwar, R. B. \& Rahmawati, D. (2017). The Use of Mathematical Module Based on Constructivism Approach as Media to Implant the Concept of Algebra Operation. IEJME Mathematics Education, 12(6), 579-583.

Kader, G. D., \& Perry, M. (2006). A Framework for Teaching Statistics within the K-12 Mathematics Curriculum. United States: ICOTS7.

Krulik, S., \& Posamentier, A. S. (1998). A Resource for the Mathematics Teacher. California: Corwin Press.

Liljedahl, P., Santos-Trigo, M., Malaspina, U., \& Bruder, R. (2016). Problem-Solving in Mathematics Education. In Problem-Solving in Mathematics Education (pp. 1-39). New York, NY: Springer.

Lim, C. S. (2002). Practice Make Perfect? An Insight into the Culture of Mathematics Learning in two Chinese Primary Schools. In Proceedings of Mathematics Education National Seminar, 163-171. 
Lipson, K. (2007). Assessing Understanding in Statistics. In B. Phillips \& L. Weldon (eds.), Proceedings of the IASE/ISI Satellite Conference on Assessing Student Learning in Statistics.

Mathematics Curriculum Framework (1996). Curricular Framework Guidance Document and Supports Mathematics. USA: New Jersey Department of Education.

Moore, D. S. (1997). New Pedagogy and New Content: The Case of Statistics. International Statistical Review, 65(2), 156-158.

Muir, T., Beswick, K., \& Williamson, J. (2008). "I'm Not Very Good at Solving Problems": An Exploration of Students' Problem Solving Behaviours. Journal of Mathematical Behavior, 27(3), 228-241.

Mushlihah Rohmah, M., \& Sutiarso, S. (2018). Analysis Problem Solving in Mathematical Using Theory Newman. EURASIA Journal of Mathematics, Science and Technology Education, 14(2): 671-681.

National Council of Teachers of Mathematics - NTCM (2000). Principles and Standards for School Mathematics. Reston, VA: NCTM.

National Council of Teachers of Mathematics - NTCM (2009). Guiding Principles for Mathematics Curriculum and Assessment. NTCM.

Pimm, D., Westwell, J., Wilder, J. S., \& Wilder, J. P. (2011). Learning to Teach Mathematics in the Secondary School. $3^{\text {rd }}$ Edition. London and New York: Routledge.

Ramachandran, K. M., \& Tsokos, C.P. (2021). Mathematical Statistics with Applications in R. $3^{\text {rd }}$ Edition. London: Academic Publication.

Santrock, J. W. (2009). Educational Psychology. $4^{\text {th }}$ Edition. Boston: McGraw-Hill.

Shah, R. K. (2019). Effective Constructivist Teaching. Learning in the Classroom. $x$ International Journal of Education, 7(4), 1-13.

Steffens, F. E., \& Fletcher, L. (1999). Statistics as Part of the Mathematics Curriculum in South Africa. In Proceedings of the $1^{\text {st }}$ International Conference of the Mathematics Education into the $21^{\text {st }}$ Century Project, 1(1), 298-305.

Steinberg, W. J. (2008). Statistics Alive. USA : SAGE Publications.

Triola, M. F. (2011). Essentials of Statistics. $4^{\text {th }}$ Edition. Boston, Massachusetts: Pearson Education.

Verhoeven, P. S. (2009). Quality in Statistics Education. Determinants of Learner Outcomes in Methods and Statistics. Dissertation. The Netherlands: Utrecht University.

Zakarie, E. (2011). Students' Procedural and Conceptual Understanding of Mathematics. Australian Journal of Basic and Applied Sciences, 5(7), 684-691. 
